\title{
Correspondence
}

\section{Coagulation disturbances and fulminant liver failure}

Sir,

In this study of one child with fulminant hepatic failure, ${ }^{1}$ time consuming and difficult assays have been used to show simultaneously features of intravascular coagulation, fibrinolysis and impaired production of factors promoting and inhibiting coagulation and fibrinolysis. The authors are to be congratulated on the thoroughness of the study, which suggests that the regenerative capacity of hepatocytes may be influenced by thrombotic occlusion of the intrahepatic microcirculation.

Their conclusion that the patient's recovery was due to the haemostatic balance they maintained during the first 15 days in hospital and their more general assertion that the prognosis for fulminant hepatic failure may be improved by these measures, can hardly be sustained on the basis of a single case report, albeit backed by five consecutive adult patients with fulminant hepatic necrosis (as yet unreported) treated consecutively in a related unit.

It should be noted that death from fulminant hepatic failure when treated in a more conventional fashion is not invariable in patients whose prothrombin activity is as high as $14 \%$. Furthermore the patient's recovery coincided with remission of renal failure which was perhaps the most striking feature of his illness and may well have contributed to his coma. Leptospirosis does not seem to have been excluded as a cause for the boy's illness, although it could explain many of the features.

My main concern about the conclusion, however, relates to the steps necessary to maintain haemostatic balance. This included the infusion of antithrombin III plasminogen, fresh frozen plasma, and prothrombin concentrates. No details are given on the preparation of these but since they are likely to be plasma derived, do they not carry a risk of causing non- $A$, non-B hepatitis, type $A$ hepatitis, or acquired immune deficiency syndrome?

I am surprised that this article was published in the Archives with the above title and conclusion.

Alex P Mowat King's College School of Medicine, London SE5 8RX

Dr Burghard and co-workers comment:

Concerning the aetiology of fulminant hepatic failure in our patient, exhaustive bacteriological and virological studies were performed, and leptospirosis, among other infections, was excluded.

Improvement of renal function was related to hepatic function returning to normal and complete correction of coagulation disturbance. It is unlikely that renal failure was the most striking feature of the patient's clinical condition, or that it contributed much to the coma for two reasons: the boy became comatose while renal function was only moderately decreased, and good metabolic and fluid balance were achieved throughout the whole period when haemodialysis was necessary.

No set guidelines are presently available for the treatment of the coagulation disturbances that occur in fulminant hepatic failure, and no controlled trial based on our treatment approach has been performed so far. A prospective investigation is difficult in respect of the small number of cases seen at any centre, and the ethical problems are evident, especially in paediatric patients. The same is true for many other procedures used in the treatment of fulminant hepatic failure on a merely empirical basis. Our conclusions are based on the successful treatment of seven consecutive patients over a 10 year period, and have been published elsewhere. ${ }^{2}$ The mortality rate from fulminant hepatic failure with more conservative treatment before this time was $100 \%$. Nevertheless, we would agree with Dr Mowat that more studies are required to determine the exact role of the proposed treatment.

The risk of serum hepatitis or even acquired immune deficiency syndrome is important when the large amounts of plasma derivatives - especially fresh frozen plasma-are considered. Similar to other aggressive treatment regimens, indications must be weighed against the increased risk of potential complications. Based on the experiences reported, however, it is our opinion that further use is justified.

\section{References}

${ }^{1}$ Burghard R, Leititis JU, Rossi R, Egbring R, Brandis $M$. Treatment of severe coagulation disturbances as a condition of improved prognosis in fulminant liver failure. Arch Dis Child 1985;60:167-70.

2 Egbring R, Seitz R, Gottesbü-en H, Burghard R, Fuchs G Lerch L. Substitutionstherapie mit Plasmaderivaten (Antithrombin III, PPSB, FFP, F VIII, Plasminogen und Kryopräzipitat) bei schweren erworbenen Störungen der Hämostase infolge akuter Leberinsuffizienz und Sepsis. In: Köstering $\mathbf{H}$, ed. Antithrombin III, grundlagen, diagnostik, klinische be deutung und therapie. New York: Schattauer Verlag Stuttgart, 1984;135-62.

\section{Formula milks for the older infant}

Sir,

I would like to comment on the recent appearance of a milk formula called Progress from Wyeth Laboratories which is being marketed as a follow on formula suitable for infants from 4 to 6 months onwards. The promotional literature quotes two references, a Department of Health and Social Security (DHSS) report ${ }^{\prime}$ and a report from the 
European Society for Paediatric Gastroenterology and Nutrition (ESPGAN) committee on nutrition. ${ }^{2}$

I feel that this milk product is undesirable because mothers in our area are tending to give it to infants less than 4 months old, perhaps in the hope of accelerating their development, and despite the recommendation on the tin. Further than that, however, I do not think the spirit of the DHSS report quoted by the manufacturers supports the need for this milk at all. Thus:

(1) The current DHSS guideline is that an approved formula be given up to the age of 6 months and at that point it is perfectly safe to change to natural cows' milk. ${ }^{3}$

(2) The report suggests that the use of an approved infant formula throughout the first year of life may be an advantage'. ${ }^{4}$ This is not suggesting a different formula from the infant milk formulas currently available. In fact Progress is not an 'approved' formula in the sense of the report since the sodium content $(39 \mathrm{mg} \%)$ is in the range of normal unmodified cows' milk of 35 to $90 \mathrm{mg} \% .^{5}$ (Maximum recommended sodium concentration for approved formulas $35 \mathrm{mg} \%$. $)^{6}$

(3) No DHSS publication recommends changing from an approved infant formula before 6 months of age; and in fact the specific recommendation is that an approved formula 'should be available for feeding up to at least the age of 6 months'. ${ }^{4}$ According to this DHSS report, therefore, a follow on formula that is not approved should not be marketed for use from age 4 months onwards.

It is true that ESPGAN recommend the replacement of the starting formula by a less expensive follow on formula at 4 to 6 months of age, ${ }^{7}$ even though ESPGAN agrees that 'after 6 months of age there is scope for different feeding regimens. The use of boiled or sterilised cows' milk or of a home made formula based on this is no longer contraindicated. ${ }^{7}$ It should be noted, however, that Progess is not less expensive (price to retailer less VAT per $450 \mathrm{~g}$, SMA Gold Cap-161.5p; Progress-162p).

Furthermore, the ESPGAN report points out the dangers of a high sodium intake even at 4 to 6 months of age, implying that hypernatraemia is still a hazard and the development of hypertension a long term risk. ${ }^{8}$ If a formula is to be used at all at this age, therefore, it would seem preferable to have a sodium content much lower than that of cows' milk as in the approved infant formulas.

In summary, I think this new milk is both confusing for mothers and unnecessary for infants and the identification of this fictitional 'nutritional gap' by Wyeth Laboratories is more likely to promote sales than child health.

\section{References}

1 DHSS. Present day practice in infant feeding 1980. (Revised 1983). Report on Health and Social Subjects No. 20. London: HMSO, 1983:5.2.1.

2 ESPGAN Committee on Nutrion. Guidelines on infant nutrition 11. Recommendations for the composition of follow up formula and Beikost. Acta Paediatr Scand 1981;Suppl 287:1-19.

3 DHSS. Artificial feeds for the young infant. Report on Health and Social Subjects no. 18. London: HMSO, 1980: Appendix 2.

4 DHSS. Present day practice in infant feeding 1980. (Revised 1983). Report on Health and Social Subjects no 20. London: HMSO, 1983:9.2.1.

5 DHSS. Artificial feeds for the young infant. Report on Health and Social Subjects no 18. London: HMSO, 1980:76.
'DHSS. Artificial feeds for the young infant. Report on Health and Social Subjects no 18. London: HMSO, 1980:78.

${ }^{7}$ ESPGAN Committee on Nutrition. Guidelines on infant nutrition 11. Recommendations for the composition of follow up formula and Beikost. Acta Paediatr Scand 1981;Suppl 287:4.

* ESPGAN Committec on Nutrition. Guidelines on infant nutrition 11. Recommendations for the composition of follow up formula and Beikost. Acta Paediatr Scand 1981;Suppl 287:8.

J F B Dossetor

Queen Elizabeth Hospital, King's Lynn PE30 4ET

\section{Statement by the Nutrition Committee of the BPA}

The Nutrition Committee of the British Paediatric Association has recently considered the use of infant formulas by the older infant.

The committee endorses the views expressed in Present Day Practice in Infant Feeding $1980^{1}$ that is '. . . the change from breast or bottle feeding to household milk is not advised before about 6 months of age. To continue with reconstituted infant formula beyond about 6 months, instead of changing to cows' milk may be beneficial. The intake of a sufficient amount of iron and of vitamins A, C, and $\mathrm{D}$ will then be assured, but when cows' milk is introduced vitamin supplements will be necessary and iron deficiency may be a problem'.

At about 6 months of age, therefore, there are three options for the bottle fed baby:

(a) To continue with the normal infant formula which the infant is receiving. These formulas are suitable for infants throughout the first year of life.

(b) To change from infant formula to a 'follow up milk'. Follow up milks, like infant formulas, contain added iron and vitamin $\mathrm{D}$. They have no nutritional advantages over normal infant formulas.

(c) To change from infant formula to pasteurised whole cows' milk; the professional adviser should be confident that an adequate supply of iron and vitamin $\mathrm{D}$ from other sources is ensured.

Skimmed milk must not be used. Children of this age are specifically excluded from recent recommendations concerning the lowering of dietary fat. ${ }^{2}$

In all cases a normal mixed weaning diet should be introduced as well.

There is no legislation specifying the composition of infant formulas. Proposals for the composition of infant formulas have been published by the United Kingdom Department of Health and Ministry of Agriculture ${ }^{34}$ and by the EEC. ${ }^{5}$ The EEC documents also contain a proposal for the composition of 'follow up milks' and uses the following description ${ }^{4}$ of infant formulas: "intended to cover on their own the nutritional requirements of infants in good health during the first 4 to 6 months after birth but which could be used up to 1 year of age if enriched with iron', follow up milks: 'intended to form the basic milk element in a diversified diet of infants older than 4 months and of young children'.

\section{References}

1 DHSS. Present day practice in infant feeding 1980. Report on Health and Social Subjects no 20. London: HMSO, 1983:17. 